\title{
P.4 MU RADAR OBSERVATION OF A MESOSPHERIC GRAVITY WAVE BREAKING CAUSED BY CONVECTIVE INSTABILITY
}

\author{
Y. Muraoka ${ }^{1}$, T. Sugiyama ${ }^{2}$, K. Kawahira ${ }^{3}$, T. Sato ${ }^{4}$, T. Tsuda ${ }^{4}$, S. Fukao ${ }^{4}$, and S. Sato 4 \\ 1Department of Physics, Hyogo College of Medicine \\ Nishinomiya, Hyogo 663, Japan \\ 2Department of Physics, Kyoto University \\ Kyoto 606, Japan
}

3Toyama National College of Technology, Toyama

Toyama 939, Japan

\section{${ }^{4}$ Radio Atmospheric Science Center, Kyoto University \\ Uji, Kyoto 611, Japan}

In our recent measurements of mesospheric winds with the MU radar at Shigaraki $\left(34.9^{\circ} \mathrm{N}, 136.1^{\circ} \mathrm{E}\right)$, Japan, we obtained a couple of wind velocity data showing that a monochromatic inertia-gravity wave was propagating vertically in the mesosphere. The data show that the velocity amplitude of the wave did not increase exponentially above a height and further show that the wave form had broken down at a level. Evaluating the changes of the atmospheric stability in the wave field from the measured wind data and from the estimated wave parameters, we were able to show that the breakdown of the wave had been connected with the occurrence of convective instability in the wave field.
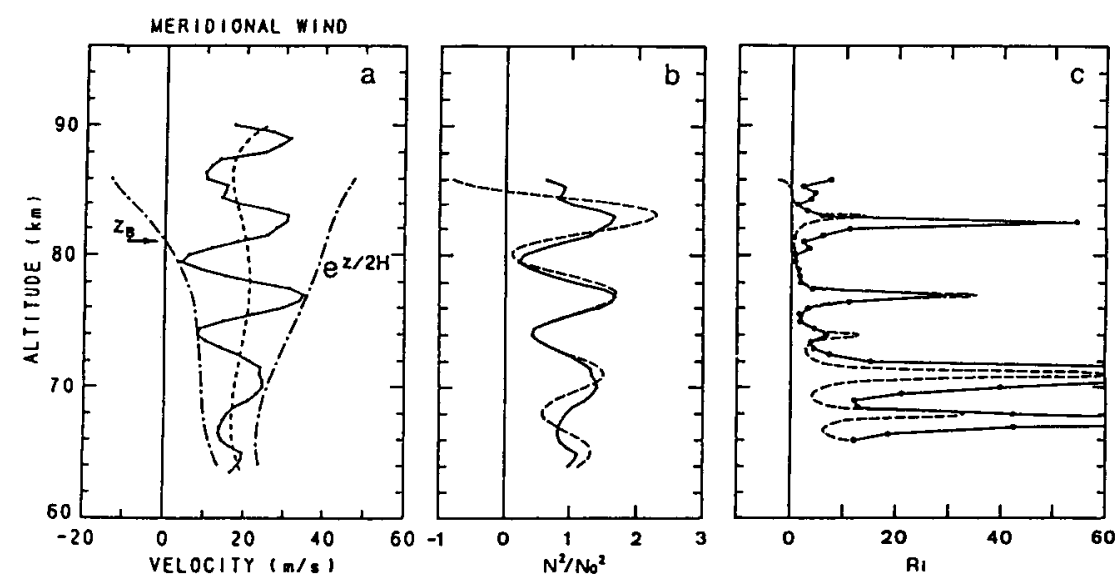

Figure 1. A comparison between height profiles of (a) meridional wind velocity, (b) normalized total static stability $\left(\mathrm{N}^{2} / \mathrm{N}_{0}{ }^{2}\right.$ ) and (c) Richardson number ( $\left.\mathrm{Ri}\right)$. In the panel (a), the full line represents the wind velocity obtained from the measurement during the period of 1430 - 1635 LT on 20 September 1985. The dashed and dot-dashed lines indicate the background mean flow and an exponential growth of the velocity perturbation, respectively. In the panels (b) and (c), the full and dashed lines represent the values evaluated from the measured wind velocity and from the estimated wave parameters, respectively. 
Table 1. Characteristics of the Gravity Wave Motion Observed in the Mesosphere on 20 September 1985 and the Related Mean Atmospheric Parameters.

$\begin{array}{lll}\text { Quantities Notations } & \text { Values }\end{array}$

Vertical wavelength

Horizontal wavelength

Period

Vertical phase velocity

Horizontal phase velocity

Ratio of the intrinsic to inertial frequency

Doppler-shifted horizontal phase velocity

\section{Wave Field}

$\begin{array}{ll}\lambda_{\mathrm{z}}=2 \pi / \mathrm{ml} & 6 \mathrm{~km} \\ \lambda_{\mathrm{x}}=2 \pi / \mathrm{k} & 400 \mathrm{~km} \\ 2 \omega / \pi & 5.6 \mathrm{~h} \\ \omega / \mathrm{m} & \begin{array}{l}30 \mathrm{cms}^{-1} \\ \text { downward }\end{array} \\ \omega \mathrm{k} / \mathrm{k} & \begin{array}{l}20 \mathrm{~ms}^{-1} \\ \text { southward }\end{array} \\ \mathrm{f} / \omega & 0.3 \\ \mathrm{c}=\omega / \mathrm{k}+\overline{\mathrm{u}} & 0 \mathrm{~ms}^{-1}\end{array}$

\section{Mean Field*}

Meridional wind velocity

$\overline{\mathbf{u}}$

$20 \mathrm{~ms}^{-1}$ northward

Vertical wind velocity

$\overline{\mathbf{w}}$

$20 \mathrm{cms}^{-1}$ downward

Brunt-Văisălä frequency

Scale height

Temperature
$0.021 \mathrm{~s}^{-1}$

$6.2 \mathrm{~km}$ $210 \mathrm{~K}$

\section{*Evaluated around $75 \mathrm{~km}$ altitude.}
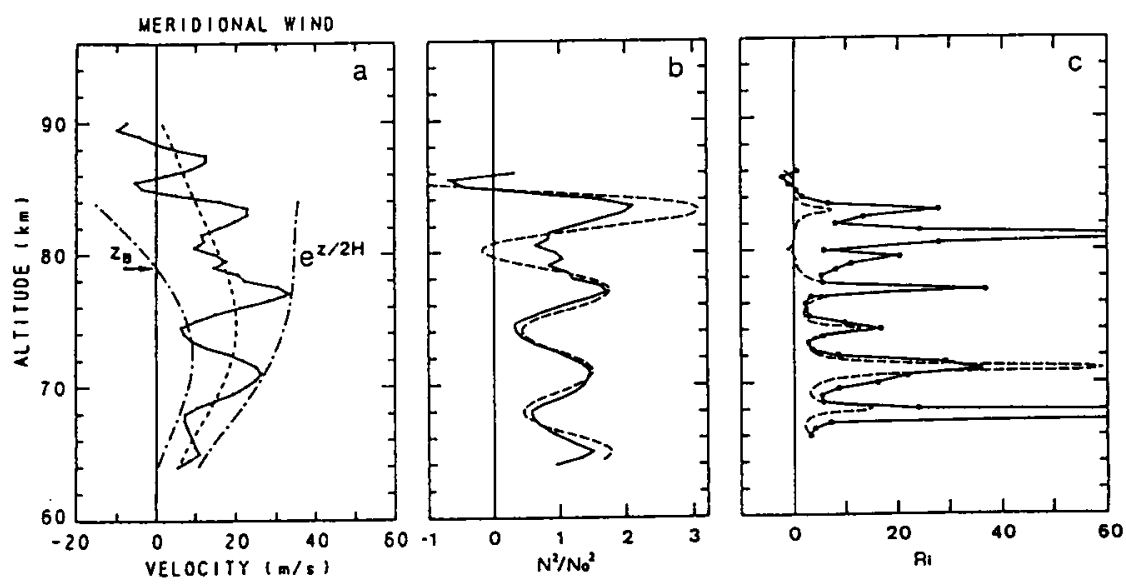

Figure 2. Same as Figure 1 except for the observation during the period of $1202-1406$ LT on 20 September 1985. 